\title{
Prêcher « à l'italienne » hors d'Italie : Jean de Capistran en Europe centrale (1451-1456)
}

Predicare 'all'italiana' fuori dall'Italia: Giovanni da Capestrano in Europa centrale

Preach "Italian-style" Outside Italy: John of Capestrano in Central Europe

Ludovic Viallet

\section{(2) OpenEdition}

Journals

Édition électronique

URL : http://journals.openedition.org/cei/5946

DOI : $10.4000 /$ cei.5946

ISSN : 2260-779X

Éditeur

UGA Éditions/Université Grenoble Alpes

Édition imprimée

ISBN : 978-2-37747-159-1

ISSN : 1770-9571

Référence électronique

Ludovic Viallet, « Prêcher «à l'italienne » hors d'Italie : Jean de Capistran en Europe centrale

(1451-1456) », Cahiers d'études italiennes [En ligne], 29 | 2019, mis en ligne le 30 septembre 2019,

consulté le 27 mars 2021. URL : http://journals.openedition.org/cei/5946 ; DOI : https://doi.org/ 10.4000/cei.5946

Ce document a été généré automatiquement le 27 mars 2021.

(c) ELLUG 


\title{
Prêcher « à l'italienne » hors d'Italie : Jean de Capistran en Europe centrale (1451-1456)
}

\author{
Predicare 'all'italiana' fuori dall'Italia: Giovanni da Capestrano in Europa \\ centrale \\ Preach "Italian-style" Outside Italy: John of Capestrano in Central Europe
}

\section{Ludovic Viallet}

Jean de Capistran avait déjà près de 55 ans lorsqu'en mai 1451 il franchit les Alpes avec douze compagnons pour parcourir l'Autriche, la Moravie, la Bohême - sans pouvoir entrer dans Prague -, les terres d'Empire (Bavière, Thuringe, Saxe), la Haute Lusace et la Silésie. Entre ses deux séjours à Breslau (Wrocław), de mi-février à août 1453 et du 29 mai jusqu'en juillet 1454, il passa plusieurs mois à Cracovie, puis mit sa parole au service de la croisade contre les Turcs et mourut le 23 octobre 1456 à Ilok (Croatie) après avoir contribué à la levée du siège de Belgrade. L'année précédant son départ, il avait obtenu la canonisation de son maître et ami Bernardin de Sienne, mort en $1444^{1}$. Le chroniqueur franciscain Nicolas Glassberger écrit que Capistran demanda conseil, avant d'aller in Alamanniam, à son compagnon (socius) Michel de Prusse, qui lui aurait rapporté les paroles des nobles: «Puisse un tel homme être avec nous, nous serions heureux en Autriche (Austria) et tout malheur serait détourné de notre terre ${ }^{2}$. » Dans une lettre du 11 janvier 1453 adressée au cardinal protecteur de l'Ordre, l'évêque de Sienne Enea Silvio Piccolomini (futur pape Pie II) écrivit au sujet de Capistran : « Frère Jean est un homme de Dieu, les peuples de Germanie le considèrent presque comme un prophète. Il pourrait s'il le voulait, en levant le doigt, créer un grand trouble [magnam turbam facere] $]^{3}$. " Ces mots invitent à souligner ce que l'on pourrait appeler le «besoin de charisme ", auquel répondit indéniablement le religieux italien - en en ayant conscience et en en usant, voire en abusant - avec des moyens et des procédés que d'autres n'utilisèrent pas, ou pas avec la même ampleur ${ }^{4}$. 
2 J'étais entré véritablement dans l'univers de prédicateur de Capistran, il y a plus d'une douzaine d'années, en m'interrogeant sur un épisode intervenu lors de son séjour à Breslau. Il y montra une image de saint Bernardin le dimanche Judica me (18 mars 1453), avec, selon le clerc Sigismond Rosicz, speculum terribile alias ein Hirnschedel (Hirn-Schädel, « crâne-cerveau »). La prédication de Leipzig, à l'automne 1452, confirme qu'il sortait parfois de son vêtement une véritable tête de mort pour la brandir devant son auditoire, en particulier au cours de ses sermons sur la mort et le Jugement ${ }^{6}$. Ce fut donc le cas à Breslau, où il précisa que le crâne était un miroir plaçant chaque fidèle face à lui-même ${ }^{7}$. D'autres sources montrent qu'il présentait à la foule la barrette d'ecclésiastique (biretum ou pileolum) de Bernardin; il le fit dès le 14 février 1451 à Brescia, dans un extraordinaire engouement populaire ${ }^{8}$. Capistran effectuait des guérisons miraculeuses au nom de Bernardin, tenant à la main la barrette de celui-ci lorsqu'il faisait sur les malades le signe de la croix au nom du Père, du Fils, du SaintEsprit et... de saint Bernardin. Il avait emporté du sang de ce dernier ainsi que, vraisemblablement, l'un de ses habits. La principale relique qu'il utilisa, toutefois, fut la fameuse barrette, qu'il faut bien distinguer du crâne présenté manifestement à la foule à plusieurs reprises. La distinction est nécessaire, car en passant de l'un à l'autre on passe d'un procédé didactique, ou de communication, à un pouvoir thaumaturgique ; en outre, au fil des jours et des mois il n'est pas certain que la confusion ne se soit pas insinuée dans les esprits de fidèles (qui ne pouvaient comprendre les paroles du prédicateur qu'à condition de saisir celles du traducteur posté plus ou moins loin d'eux). Il semble qu'au début du xvII siècle, en effet, si l'on se base sur le récit de Johann Jacob Vogel, annaliste de la ville de Leipzig, dont l'erreur peut fort bien témoigner de toute une tradition, le crâne-miroir de la mort ait été considéré comme la tête de Bernardin.

3 En définitive, le réformateur a fait, pour ainsi dire, du neuf avec du vieux. Lorsqu'il élevait la relique du saint pour la présenter à la foule et que celle-ci s'exclamait «Miséricorde! Miséricorde!» (comme le 14 février 1451 à Brescia ou en août 1452 à Arnstadt $\left.{ }^{10}\right)$, Capistran renouait avec les pratiques de disciplinamento mises en œuvre deux siècles auparavant dans les cités italiennes, en une pastorale et un rapport au Sacré au sujet desquels on peut parler d'" archaïsme innovateur » - un " archaïsme " qui fut aussi « rénovateur » et constitua le pendant de la "restauration innovatrice ${ }^{11}$ " incarnée par le projet des Observants sur le plan social. Ce que l'expression " prêcher "à l'italienne" » doit permettre de souligner, c'est qu'il s'est agi pour Capistran et ses compagnons d'utiliser un art élaboré, certes, par les prédicateurs italiens, mais aussi dans le contexte des cités italiennes, différent de celui des villes germaniques et centreeuropéennes où il fut transposé ; un art, enfin, porté par des religieux mendiants, qui fut en particulier mis au service d'une réforme franciscaine, celle de l'Observance sub vicariis dite " cismontaine » considérée par les contemporains, à tort ou à raison - mais surtout à raison - comme étroitement liée aux " pères italiens ».

\section{Une pastorale « italienne »}

\subsection{Une pastorale de la réforme}

4 L'un des principaux intérêts pour l'historien de la vie religieuse et sociale de la fin du Moyen Âge, dans l'action des prédicateurs de l'observance, réside dans la conception 
qu'ils se faisaient de la reformatio, destinée à déborder très largement hors des murs des couvents. Réformer les ordres religieux et réformer la société (régénérer la societas christiana sur le modèle du cloître) ont été conçus, au xv siècle, comme deux ambitions étroitement liées, en particulier chez les Mendiants, dont l'intensification de l'effort pastoral ne peut être dissociée de la promotion des réformes de observantia. Dans sa chronique, Pierre Eschenloer écrit qu'en 1453 Jean de Capistran "enflamma les habitants de Breslau du zèle de la dévotion, puisqu'ils furent considérés non comme des citoyens mais presque comme des religieux ${ }^{12}$ ». Fondation d'un nouveau couvent, réforme morale et disciplinaire, action de pacification... le franciscain italien ne fit pas, en Silésie, autre chose que ce qu'avait fait Bernardin de Sienne vingt ou trente ans auparavant en Italie, mis à part l'usage massif des miracles au nom, justement, de Bernardin. Même le bûcher des Juifs de Breslau, accusés de profanation de l'hostie et du meurtre rituel d'un enfant chrétien, reposa sur des accusations stéréotypées diffusées en Occident depuis la fin du XIII ${ }^{\mathrm{e}}$ siècle. Capistran était alors engagé dans la controverse de l'Heiliges Blut de Wilsnack (des hosties qui saignaient, comme saignait l'hostie profanée par les Juifs); il était obsédé par l'élimination de l'hérésie bohémienne et de l'Église utraquiste, qui étaient des atteintes à l'intégrité de la communauté chrétienne comme à l'autorité de l'Église romaine. Le Juif profanateur était aussi blasphémateur, puisque le franciscain italien a également utilisé l'accusation de blasphème contre le Nom de $\mathrm{Dieu}^{13}$. Son ennemi était tout obstacle à l'achèvement de la societas (ou res publica) christiana, en une conception qui ne différait guère, en son essence, de la métaphore sociale du corps mystique paulinien et, par exemple, de la purgatioamputatio que prônerait à la fin du siècle Geiler de Kaysersberg pour le corpus reipublicc ${ }^{14}$. Toutefois, la prédication «efficace» caractéristique des Mendiants avait désormais atteint son degré extrême. De la monstration de la barrette de Bernardin jusqu'aux massacres de Juifs, l'action de Capistran et de son entourage eut une totale cohérence dont la dimension économique, souvent invoquée à propos des observants italiens, ne doit pas prendre le pas, dans les analyses, sur la dimension dévotionnelle et pastorale, poussée à son point ultime dans le contexte particulier de la tournée en Europe centrale. Au printemps 1453, la persécution des Juifs de Silésie constitua ainsi non seulement le prolongement ou la conséquence de la pastorale du franciscain italien, mais l'un de ses éléments constitutifs, en une violence exemplaire, c'est-à-dire intégrée dans une séquence à valeur d'exemplum : une histoire simple à la fin édifiante.

5 En travaillant sur les réformes de l'observance, je voudrais aussi essayer de cerner comment se sont accélérés les processus de mutation, de cristallisation et de transfert qui, à un moment donné, ont abouti au passage de la magie maléfique à la sorcellerie satanique, "sabbatique " peut-on dire, et à la constitution (donc la dénonciation) de ce crime. Pour l'histoire de la sorcellerie en Occident, il s'est passé quelque chose dans la première moitié du xve siècle, au cours du Grand Schisme et des conciles de Constance et Bâle, au moment, aussi, de la montée en puissance des dynamiques réformatrices de observantia, particulièrement au sein des ordres mendiants. Au-delà de la seule concomitance, il est impossible de n'envisager aucune relation entre les phénomènes. Pour espérer appréhender le lien entre réforme religieuse et émergence de la figure du sorcier - ou, de plus en plus, de la sorcière -, il faut essayer de mieux cerner le rôle qu'ont pu jouer les promoteurs des réformes de l'observance dans la construction et la progression d'une obsession en forme de diabolisation du monde, le projet réformateur observant s'étant nourri de la dénonciation de l'hérésie et de la répression de l'hétérodoxie, réelle ou fantasmée - et à ce titre, la figure du sorcier ou de la sorcière 
ayant été constituée en figure de l'ennemi absolu. Par-delà les traités des clercs et des juges, ou plutôt en deçà des textes qui donnèrent forme à des motifs, véhiculèrent des croyances et constituèrent le soubassement d'une répression séculaire, il y eut une action pastorale et des prises de parole, mises en œuvre avec une intensité croissante par des hommes partageant un projet et une vision du monde modelés, voire structurés dans la conscience de l'urgence du combat contre le diable. Cela n'est pas propre aux prédicateurs-réformateurs italiens; mais l'espace sur lequel sont apparus les premiers foyers de répression de la sorcellerie satanique, dans l'arc alpin, est un espace qui a été traversé par des lignes de rivalités entre des pouvoirs politiques comme entre des mouvements réformateurs - y compris à l'intérieur de l'ordre franciscain - et qui a été, pour ainsi dire, irradié par la véritable "pile nucléaire» qu'a constituée l'Observance franciscaine en Italie du Nord et du Centre ${ }^{15}$.

Cette obsession de la présence et des assauts du diable est indissociable d'une insistance exercée avec une intensité sans doute inédite jusqu'alors sur un phénomène très ancien, le discernement des esprits (discretio spirituum) ; elle est indissociable, aussi, d'une autre obsession, véritable hantise, celle de l'idolâtrie. On touche ici à une dimension essentielle de la prédication des observants, en particulier franciscains : la dimension visuelle.

\subsection{Une pastorale du visuel}

7 Au cours de la décennie 1420, Bernardin propagea la dévotion au Nom de Dieu dans les cités italiennes, grâce à sa fameuse Tavoletta portant les lettres JHS (Jesus Hominum Salvator, avec une croix sur la haste $d u$ « $\mathrm{H} »)$ inscrites dans un soleil doré. Le monogramme du Christ était une arme contre les démons; là encore, ce n'était pas nouveau. Pour le prédicateur siennois, il s'agissait également de lutter contre les incantations magiques et les superstitiones, mais aussi certainement contre le culte des fausses reliques (on peut penser que la défense de l'hostie miraculeuse, qui ne brûlait pas dans le feu, avait aussi cette fonction). L'ostension de la Tavoletta entraînait l'agenouillement de la foule, en une véritable mise en acte du verset paulinien « $\mathrm{Au}$ nom de Jésus tout genou se plie» (Phil. 2, 10). En juin 1441, la mendiante espagnole Marie de Saint-Vincent, arrêtée et exécutée pour sorcellerie dans le village de Césanne (aujourd'hui Cesana Torinese, en Italie), déclara que le diable lui avait imposé de ne pas faire le signe de la croix ni prononcer le Nom de Jésus car « quand ils l'entendaient, luimême et tous les démons de l'Enfer étaient torturés, s'inclinaient et fléchissaient les genoux ${ }^{16} »$. Marie arrivait d'Italie; sans doute ce fragment d'aveux témoigne-t-il de l'écho de sermons, assimilés au moins par bribes.

Le succès de Bernardin s'accompagna à partir de 1426-1427 d'une intense controverse, puisque le prédicateur siennois fut accusé d'hérésie, d'être l'Antéchrist et d'inciter les fidèles à l'idolâtrie, de les éloigner de la dévotion à la Croix comme de la piété eucharistique ${ }^{17}$. À travers les accusations portées contre ceux qui utilisaient le Nom de Dieu avec une dimension visuelle, il était question du rapport à l'adoration, à la latrie (latria), à l'idolâtrie (idolatria), en une époque où désormais celle-ci et toute pratique magique étaient conçues comme indissociables de l'adhésion à Satan. Pourtant, l'utilisation des lettres pour dire Dieu, la divinité du Christ et le rendre présent, apporter sacralité et protection, avait une longue histoire, comme le montrent notamment les usages des chrismes - « suspendus entre la possibilité de nommer et la 
possibilité de représenter »- bien avant le $\mathrm{xV}^{\mathrm{e}}$ siècle ${ }^{18}$. Alors, où pouvait donc bien se situer le problème, qui expliquerait ce raidissement, cette méfiance sur le Nom de Dieu, l'associant à la magie et à l'idolâtrie ? Jeanne d'Arc l'invoquait fréquemment, marquant certaines de ses lettres d'un Jhesus, mais le soupçon que l'on fit peser sur sa personne même et la nature de sa mission suffit à discréditer ses dévotions comme ses pratiques. Dans l'action de Bernardin et son usage du monogramme, et à moins de croire que tout, dans cette affaire, fut question de rivalités entre ordres religieux et de règlements de compte entre vedettes de la prédication, il faut chercher plus loin: du côté du soleil, d'une part, qui entourait les trois lettres IHS et pouvait nourrir assez aisément des accusations d'hétérodoxi ${ }^{19}$; plus largement, ou plus profondément, du côté du statut et des conceptions de l'image et du signe, objets de tensions qui sont sans doute révélatrices d'enjeux essentiels à l'aube de la Modernité - ou de l'émergence de notre modernité, à la fin du Moyen Âge et au début de l'époque moderne. Elles le sont au même titre qu'un autre phénomène, l'exigence - qui se manifesta au sein des ordres religieux, et surtout des Frères mineurs, avec une intensité inégalée - d'identification donc d'identité (le monogramme IHS devint un véritable signe identitaire de l'Observance franciscaine sub vicariis, en particulier " cismontaine »), dans un monde où la séparation entre le symbole et le signe, de même que les usages et les pouvoirs des noms (entre désignation et invocation), n'avaient pas encore été pleinement clarifiés.

Ce n'est pas le lieu, ici, de s'aventurer sur de très vastes territoires touchant en particulier à l'iconicité de l'écrit ; il faudrait pour cela, en outre, d'autres compétences que celles d'un historien des pratiques sociales et religieuses. Je m'en tiendrai à souligner que l'on touche là à des problèmes qui sont ceux de la maturation de la conscience identitaire, de la réflexion sur la relation entre signifiant et signifié et, audelà, de certaines formes de communication culturelle ${ }^{20}$; et que dans le contexte du Xv siècle, ces problématiques ont certainement été sources de secousses, en contribuant à nourrir les grandes hantises d'une société chrétienne exposée aux rayons aveuglants de Satan $^{21}$.

10 Il faut de toute façon bien avoir à l'esprit que cette pastorale du visuel, du spectaculaire, mais aussi du miraculeux, fut loin de faire l'unanimité parmi les contemporains. Dans le contexte même de la Grande Mission, l'action de Capistran et de ses compagnons a été présentée comme une stratégie et dénoncée comme une véritable supercherie par leurs adversaires, tel Matthias Döring dans un passage violemment critique de la Continuation de la Chronique de Dietrich Engelhusen. Soulignant l'hypocrisie de religieux qui prônent le mépris du monde, mais réclament d'être accueillis comme des personnages importants, il décrit la façon dont sont abusés les fidèles :

Afin que la foule le vitt, il avait coutume de célébrer des messes en des lieux profanes préparés avec grand faste pour cela sur le marché des villes, dans lesquelles il y avait pourtant nombre d'églises consacrées et de monastères, et il ne prêchait en aucun lieu qui n'ait été beaucoup rehaussé et orné. [...] et si quelque individu avec un membre atrophié ou quelque boîteux, par une confiance née de la rumeur propagée par les messagers pensait se tenir mieux, ses compagnons le pressaient de s'avancer, criant et appelant le peuple à crier « Jésus » avec grand tumulte ; ils emportaient leurs bâtons et béquilles et les suspendaient dans l'église devant l'image de saint Bernhard [sic]. Le bruit courait toutefois que beaucoup de ces [infirmes] ainsi guéris retombaient et réclamaient leurs bâtons. Il reçut de nombreux nouveaux membres dans sa famille, de toute provenance, et afin de les rassembler demanda des lieux aux seigneurs et aux communautés pour construire 
des monastères appelés de l'observance, et réussit à causer un grand trouble dans et autour de la province de Saxe ${ }^{22}$.

11 Ministre de la province franciscaine de Saxe pendant plus d'un tiers de siècle (1427-1461), Döring était un adversaire de Capistran et, à la fin de sa vie, très ouvertement hostile à Rome. Toutefois, bien des critiques furent faites aux observants par les promoteurs d'une piété et d'une dévotion fondées sur le sentiment et l'intellect plus que sur le visuel et le surnaturel, mais aussi par les milieux « humanistes ». Étant donné le soin mis par Capistran à organiser la mémoire de sa Geste, ce type de témoignage pose aussi un problème que les historiens rechignent à formuler, par crainte de l'anachronisme et parce qu'ils savent qu'il est toujours dangereux de procéder par réponses tranchées dans le domaine des mécanismes de la croyance et des relations entre le vrai et le faux au $\mathrm{xv}^{\mathrm{e}}$ siècle : le problème de son honnêteté. On sait que les médiévaux n'ont ignoré ni le cynisme, ni la manipulation. Jusqu'où Capistran et ses compagnons sont-ils allés réellement? Il n'est pas sûr, en tout cas, que l'on puisse utiliser les mêmes chemins que Marc Bloch dans le chapitre final des Rois thaumaturges, et expliquer de la même façon (pour paraphraser le titre de ce chapitre) «Comment on a cru aux miracles de Capistran ${ }^{23} »$.

\subsection{Une pastorale de la performance}

12 L'intervention du prédicateur-pasteur n'était pas fondée sur de seuls actes de discours, mais également sur le charisme, le spectaculaire, l'efficacité. Le spectre de ces pratiques de l'efficacité pouvait être assez large. Ainsi, lors d'une prédication à Brüx (Most), en Bohême, en avril 1452, Capistran aurait étendu ses bras vers le ciel en se tournant dans toutes les directions et proclamé solennellement qu'en tant que vicaire général de l'Observance il recevait dans la confraternité de l'Ordre l'ensemble des fidèles du monde entier ${ }^{24}$. Un tel geste fut motivé par le calendrier, puisqu'on était à la Pentecôte ; sauf à considérer qu'il s'est agi d'un simple artifice de prédicateur, il illustre une conception maximaliste de la famille spirituelle franciscaine, que Capistran tendit à faire se confondre avec l'Ecclesia puisque, de même que tous les chrétiens avaient vocation à recevoir l'Esprit saint, tous étaient appelés à entrer dans la solidarité des bienfaits initiée par François d'Assise. On pouvait difficilement affirmer avec plus de force et de clarté la prétention universaliste d'une pastorale conquérante, celle de l'Observance. Mais en outre, l'association aux mérites de l'Ordre résultait normalement d'un acte officiel réalisé par le ministre ou le chapitre, général ou provincial, lettre de confraternité à la clef. Or, aucun document écrit ne nous est parvenu, ce qui ne surprendra pas forcément: on est bien là face à un usage de la parole et du geste qui confina à l'efficacité, en ce sens qu'ils étaient censés opérer en eux-mêmes et dans l'instantanéité. Cela témoigne, chez Capistran comme chez d'autres vedettes du temps (Jacques de la Marche, notamment), d'une grande liberté dans les pratiques qui n'était pas sans dégâts collatéraux - notamment, la banalisation de la notion de confratria - et ne peut s'expliquer par la seule griserie d'un succès populaire annihilant tout contrôle de soi.

13 Certes malaisé à appréhender, l'acte de prédication $\mathrm{du} \mathrm{Xv}^{\mathrm{e}}$ siècle peut être considéré dans sa dimension performative - par le biais, pourquoi pas, d'outils issus de l'anthropologie de la performance ou de la sociolinguistique - et il peut être comparé à celui $d u x^{e}$ ou du début du $x x^{\mathrm{e}}$ siècle, extrêmement présent, en particulier, dans la sphère du pentecôtisme contemporain ${ }^{25}$. Cependant, si le mécanisme de l'efficacité de 
la parole du prédicateur a résidé avant tout dans le caractère éminemment performatif de la prédication, effectuée comme une séquence assimilable au «drame social » de Victor Turner, il faut impérativement considérer que l'intervention du prédicateur s'inscrit dans le cadre d'un agencement particulier d'éléments, un contexte qui fait texte - selon le mot de Letizia Pellegrini ${ }^{26}$.

Le modèle de pastorale que l'on peut qualifier d'« observante ", c'est-à-dire fondée sur une prédication de performance et d'efficacité symbolique, était un type qui avait fait ses preuves en Italie, dans le contexte des cités-États du Quattrocento, caractérisées par une structuration et des dynamiques des pouvoirs politiques bien spécifiques, une particulière densité de la présence des ordres mendiants, la fréquence de leur prédication, ainsi que par des structures urbanistiques et un mode de vie encourageant les formes de la sociabilité dans l'espace public ${ }^{27}$. Ce modèle obtint du succès auprès des foules d'Europe centrale, certes, mais rencontra un obstacle qui était celui du pouvoir local: la prédication de Capistran était légitimée par le pouvoir thaumaturgique du saint (Bernardin) ou de celui qui était vu comme tel (Capistran), mais aussi par le jeu diplomatique ; entre ces deux niveaux, toutefois, elle n'était pas véritablement enracinée et restait une prise de parole transplantée.

\section{Une pastorale hors d'Italie}

\subsection{Réformes observantes et pouvoirs}

On sait bien que la réforme religieuse portée par les mouvements observants du $\mathrm{xv}^{\mathrm{e}}$ siècle a été conçue et mise en œuvre en lien étroit avec les pouvoirs - et en une relation de partenariat entre ceux-ci et les prédicateurs -, au service de la légitimation de l'ordre social, de la normalisation des comportements et de la lutte contre la déviance. La Mission de Capistran entrait en résonance avec les aspirations à la reformatio, en particulier avec celles des princes. Un mot allemand, celui de Kirchenpolitik, exprime bien comment les pouvoirs princiers pouvaient s'emparer de la réforme religieuse. Un très bon exemple en est fourni par la maison de Wettin, qui, en Thuringe, noua une relation forte avec l'observance franciscaine à partir de 1449 et de l'instauration du premier vicaire observant de Saxe. À Iéna, en septembre 1452, le landgrave Guillaume III rencontra Jean de Capistran, qui lui apporta un soutien important. Guillaume poursuivit et amplifia le projet de réforme de son père, marqué notamment par la volonté d'imposer dans la population certaines normes de discipline religieuse et morale (respect du repos dominical, mesures contre les vêtements et la nourriture de luxe, interdiction des jeux de dés) ${ }^{28}$.

Toutefois, le projet de Capistran était certainement plus « appropriable » et acceptable par des pouvoirs princiers que par ceux des villes. Le rôle des autorités urbaines a été majeur, particulièrement dans un espace germanique où le critère du «besoin social ", de l'Utilitas publica et de la participation au bien commun (Gemeinwohl) a occupé une place croissante et influencé largement le positionnement des cités en faveur de choix réformateurs relevant d'une voie moyenne. Par rapport à l'espace français et aux "bonnes villes", notamment, où la réforme des communautés régulières apparaît avant tout comme une variable des pouvoirs, dans le monde germanique elle fut davantage un véritable levier du pouvoir. En Occident, en effet, les villes soutinrent épisodiquement, sur le plan matériel, les communautés de conventuels ; l'essentiel de 
leur aide passa toutefois par les gestes de piété. Quand l'Observance arriva, elle fut acceptée ou rejetée, au gré des contextes locaux, des rapports de forces et des intérêts économiques. La situation des couvents germaniques fut différente, car le contrôle exercé par la ville est visible dès le XIV ${ }^{\mathrm{e}}$ siècle et s'accentua grâce au lien institutionnel que constituaient les Verweiser, Kirchväter et autres Pfleger, représentants du gouvernement urbain chargés de la gestion des affaires du couvent. Cela fut encore plus vrai pour les communautés relevant des Reformaten, mouvement réformateur (observant) de " voie moyenne » - nous allons y venir. L'analyse de la gestion des biens matériels fait apparaître une véritable appropriation, par les gouvernements urbains, de leurs communautés franciscaines ${ }^{29}$. On pourrait multiplier les exemples dans les villes germaniques, de Bâle à Ulm en passant par Dresde, ou encore en Silésie et Haute Lusace, ces deux derniers espaces offrant peut-être des cas extrêmes, car les intérêts et tensions politico-ethniques, liés à l'influence de la couronne de Bohême et à la proximité avec le monde tchèque, y jouèrent un rôle important. Les couvents de Mineurs ne furent pas les seuls à connaître ce phénomène aux allures de véritable «municipalisation »; ils y étaient toutefois exposés de façon privilégiée compte tenu $\mathrm{du}$ propositum vitoe et des projets réformateurs franciscains, particulièrement perméables, voire malléables au contact du monde laïque étant donné, notamment, la place qui y était faite à la question des intermédiaires - « personnes interposées » dont la présence et le rôle, malgré l'interdiction primitive de François, ne cessèrent jamais d'être au cœur des relations des frères avec l'argent et les biens matériels.

\subsection{Comment la ville se pense}

17 La différence entre deux «modèles » ou «types » de relations entre les Universitates urbaines et les communautés régulières n'est pas facile à expliquer; elle dit sans doute quelque chose sur la façon dont la ville se pensait, dont ses élites la concevaient à l'aube de la Modernité.

Il s'agit d'une distinction qui fait penser à une autre, héritée de Ferdinand Tönnies et Max Weber, entre "communalisation» (Vergemeinschaftung) et "sociation" (Vergesellschaftung). Toutefois, outre que les «idéaux-types " sont, par définition, des idéaux (et des types...), dans les villes du $\mathrm{xv}^{\mathrm{e}}$ siècle le vivre ensemble n'était jamais fondé sur l'échange économique strictement rationnel (l'un des types les plus purs de la sociation, induite par le "compromis d'intérêts", selon Weber). Par ailleurs, avec les manifestations religieuses à dimension communautaire que les médiévistes qualifient souvent, depuis les années 1990, de "religion civique», les villes d'Occident ont largement entretenu le sentiment d'appartenance par l'affectif et l'identité, cette condition nécessaire de la communalisation - définie par le fait d'avoir quelque chose en commun (Gemeinsamkeit) et par le développement du sentiment d'appartenance commune (Gemeinsamkeitsgefühl) ${ }^{30}$. Pour mieux cerner ce qui a pu caractériser la relation entre les villes germaniques et les institutions régulières, en particulier les couvents mendiants, et donner à cette relation une intensité spécifique, plus forte qu'en Occident et poussée jusqu'à une forme d'inclusion, il faut sans doute aller chercher du côté de l'importance croissante de la notion de bien commun (Gemeinwohl) dans le projet idéologique des élites au pouvoir, et du rôle du concept politique du « commun profit » ou « utilité commune » (Gemeine Nutzen) au service de la légitimation des autorités en place ${ }^{31}$. 

explique, au moins en partie, le soutien apporté par des villes à des proposita réformateurs relevant d'une voie moyenne, à bien des égards rationnelle voire raisonnable. Il n'est pas possible de dissocier les problèmes liés à la gestion de la ville et de son espace de la question de la "bonne réforme ", à partir du moment où, en outre, celle-ci faisait revenir dans le giron municipal certains biens fonciers ou immobiliers ou, au contraire, signifiait pour la ville un surcroît de dépenses induites par le nécessaire soutien à une communauté refusant tout revenu régulier. Il faut avoir cela à l'esprit lorsque l'on fait le constat, au-delà de la popularité personnelle du prédicateur Jean de Capistran, des limites de la réussite de sa Grande Mission dans les années 1452-1454. Le refus d'une réforme trop extrême, et corrélativement le choix d'une réforme de via media ont été directement déterminés par les politiques de bien commun et d'utilité publique; plustard, les positionnements des villes par rapport aux mouvements réformateurs "protestants" ne peuvent être analysés en faisant abstraction de la priorité donnée à l'utilité publique.

J'avais quasiment posé comme véritable préalable à mon enquête, il y a plusieurs années, le refus d'invoquer trop facilement et naturellement la tendance, naguère signalée par Bernd Mœller, qu'eut la ville allemande de la fin du Moyen Âge à se considérer comme un "corpus christianum en miniature», qui aurait sous-tendu le regard qu'elle posait sur elle-même ${ }^{32}$; donc, aussi, de la reprendre un peu comme un argument en forme d'auctoritas pour expliquer l'implication des autorités urbaines dans la réforme des couvents franciscains. Il faut continuer à refuser un type d'explication "tautologique ", voire téléologique, décrivant et analysant les phénomènes tardomédiévaux à la lumière de l'avènement de la Réforme. Toutefois, on doit bien reconnaître la force du faire communauté et la conception « organiciste » qui s'affirma dans les villes du monde germanique, et dont témoignent nombre de manifestations de leur vie politique et judiciaire ${ }^{33}$. Ce que Pierre Monnet a appelé «processus de religiosité transformée, communalisée", qui s'est accompagné d'un surcrô̂t de contrôle social et disciplinaire, a-t-il entraîné une "sécularisation des valeurs religieuses » ou un « sursaut paroxystique du sacré34 ${ }^{34}$ ? Sans doute les deux à la fois... Et c'est dans ce cadre qu'il faut s'efforcer de penser les réformes régulières, et les prises de parole qui les étayaient.

21 En définitive, pour dire les choses très simplement, si la prédication exportée dans le monde germanique et en Europe centrale fut « italienne », elle fut mise en œuvre dans des cités qui ne l'étaient pas. Il reste en outre à souligner que cette pastorale élaborée par des religieux venus de la Péninsule et dans le contexte des cités du Quattrocento fut mise au service, par Jean de Capistran et ses proches, d'une réforme franciscaine qui était celle de l'observance sub vicariis et cismontaine, conçue en Italie et perçue, par les contemporains, comme étroitement liée aux milieux italiens.

\section{Un projet réformateur}

Les années 1440-1450, qui ont été le cadre de la canonisation de Bernardin de Sienne, ont été aussi celles de l'institutionnalisation décisive d'un mouvement réformateur autonome par le biais de la création de vicairies (dirigées par des vicaires) et d'un véritable changement de climat au sein de l'ordre franciscain : la recherche de solutions encore consensuelles a laissé place à des tensions nettement plus fortes et à des

Cahiers d'études italiennes, 29 | 2019 
comportements plus radicaux, notamment dans le contexte de la tournée de Capistran et ses disciples en Europe centrale. Or, chez ce dernier, la promotion de la sainteté de Bernardin et celle du système vicarial furent liées.

On sait aujourd'hui que le positionnement de Bernardin, dans le processus de distinction entre "observants " et " conventuels " à l'œuvre au cours des décennies 1430-1440, n'a pas été aussi tranché que ce que les constructions postérieures de l'historiographie franciscaine ont pu faire croire. La proclamation de sa sainteté, et plus encore l'usage que fit Capistran de cette sainteté, l'amenèrent davantage du côté de l'observance sub vicariis. Capistran a structuré avant tout l'ensemble dit " cismontain », polarisé ab origine sur la péninsule italienne et s'étendant sur l'Europe centrale, les Balkans et la Terre sainte, tandis que les vicairies de la partie occidentale du monde franciscain, de l'ouest de l'Allemagne actuelle jusqu'à l'Irlande, relevaient de l'observance «ultramontaine »- dotée de Constitutions propres en 1451 à Barcelone. En même temps qu'il faisait de la sainteté de Bernardin la pierre angulaire de son charisme de thaumaturge en Europe centrale, Capistran propageait la dévotion bernardinienne hors d'Italie, mais il arrimait aussi définitivement la figure de son maître et ami à l'observance des vicaires. Il faisait de la sainteté de Bernardin une sainteté identitaire, un instrument de combat au service de l'Observance sub vicariis ; par là même, elle était tirée hors du consensus. En effet, si l'importance qu'il lui fit jouer marqua d'une forte empreinte la façon dont fut perçue l'observance sub vicariis (en Silésie et en Pologne, les franciscains réformés reçurent le nom de «bernardins »), les critiques existaient encore au début du $\mathrm{XVI}^{\mathrm{e}}$ siècle. Elles concernaient la sainteté même du prédicateur siennois (qui n'aurait jamais été canonisé si la papauté n'avait pas voulu faire ce cadeau à l'observance) ou, à tout le moins, son appropriation par l'observance des vicaires, comme en témoigne la chronique bohémienne du frère Michel de Carinthie ${ }^{35}$. Le ministre provincial de France Boniface de Ceva put ainsi déclarer, avec un sens certain de la polémique, que Bernardin étant mort dans l'obéissance aux ministres « inter ipsos fratres vicarianos nullus unquam sanctus extitit canonizatus ${ }^{36}$ ».

Boniface de Ceva était un " colétan ", c'est-à-dire qu'il appartenait à cette branche de l'Ordre qui s'était structurée autour de la personne et de la figure d'une réformatrice des Clarisses, Colette de Corbie (stricte contemporaine de Bernardin de Sienne, morte en 1447) et développée particulièrement sur un espace allant de la France du Sud-Est à la Flandre. Les colétans suivaient les Constitutions dites "martiniennes" de 1430, refusées et assouplies dans un premier temps par Matthias Döring, puis érigées en référence pendant des décennies pour ceux que l'on a appelés, dans les provinces franciscaines de Saxe et à un degré moindre de Cologne, les Reformaten. On est là face à des mouvements qui, au sein des Frères mineurs, revendiquèrent d'être de observantia, furent reconnus comme tels dans une partie de la population, mais refusèrent d'adhérer aux structures institutionnelles autonomes mises en place par l'observance sub vicariis à partir des années $1440^{37}$. Pour justifier le refus de la rupture avec les ministres provinciaux, ils mirent en avant celui de la désobéissance ${ }^{38}$.

$\mathrm{Au}$ cours de la seconde moitié du $\mathrm{Xv}^{\mathrm{e}}$ siècle, et jusqu'à la scission de 1517, dans les espaces français et germanique actuels, l'observance sub ministris, sous sa forme " colétane » ou celle des Reformaten, a été une option rivale de l'observance sub vicariis, sinon supérieure. Dans le monde germanique, le dynamisme de la réforme des Reformaten avait pris sa source dans l'activisme du provincial saxon Matthias Döring et son opposition à Capistran. Döring avait été résolument du côté du Concile face au pape 
- jusqu'à être, au pire de la crise, général de l'Ordre pour le parti conciliaire. Après 1449, l'espace allemand fut imprégné d'un important sentiment anti-romain, nourri par le concordat de Vienne et la fiscalité pontificale. L'opposition d'un mouvement d'observance sub ministris à l'observance des vicaires promue par Capistran ne peut pleinement se comprendre qu'en prenant en compte la prégnance des idées conciliaires et la montée en puissance des Églises « nationales », nourries par la critique anti-romaine. Cela est vrai également pour l'espace français actuel, où les colétans bénéficièrent du soutien du duc de Savoie, du duc de Bourgogne et du roi de France. Dans les dynamiques de morcellement institutionnel du début du xvI ${ }^{\mathrm{e}}$ siècle au sein de l'ordre franciscain, partout, depuis la péninsule Ibérique jusqu'à la Hongrie en passant par la Savoie, selon des degrés divers, la réaction - faite de distanciation, voire de franche résistance - aux pressions des réformateurs italiens joua un rôle. Ce fut certes le refus d'un certain modèle observant, fondé sur une pastorale de la performance et forgé dans les années 1430-1450 par les pères de l'Observance cismontaine, les "pères italiens " évoqués par Capistran en janvier 1455 dans une lettre aux frères de Cracovie $^{39}$; mais ce fut aussi le refus d'une vision du monde, celle de la catholicité romaine, exaltant en particulier la supériorité du pouvoir pontifical.

Ainsi l'avènement des maîtres de la parole ${ }^{40}$, le développement d'une véritable discipline et d'un système de communication aux potentialités poussées très loin pouvaient-ils susciter le rejet, voire porter en eux les germes de leur propre rejet, à partir du moment où un art de la prédication avait destin lié avec les forces mêmes qui lui avaient permis d'exister. Marquée par des réussites, mais aussi par d'importantes limites, la mission de Jean de Capistran ne peut être jugée avec les seules catégories du succès ou de l'échec. Ses effets doivent être envisagés sur la durée, celle des décennies qui se sont écoulées entre l'explosion d'un très fort engouement populaire sur le passage du (proto-)saint et l'implosion de l'ordre des Frères mineurs comme de la Chrétienté romaine en 1517. Si elle a influé sur les dynamiques réformatrices globales au sein de la famille franciscaine, la Grande Mission n'a certainement pas été sans répercussions sur l'histoire européenne au cours des soixante ou soixante-dix ans qui l'ont suivie, car elle a contribué, dans le monde germanique, à préparer le terrain aux ruptures fondatrices des années 1520 .

\section{BIBLIOGRAPHIE}

BÉRIOU Nicole, L'avènement des maîtres de la parole. La prédication à Paris au XIII siècle, 2 vol., Paris, Institut d'études augustiniennes, 1998.

Binl M., « Fra Bonifacio da Ceva († 1517) e i suoi giudizi su Bernardino da Siena », Studi Francescani, vol. 42, 1945, p. 132-172.

BLICKE Peter, "Der Gemeine Nutzen. Ein kommunaler Wert und seine politische Karriere ", dans H. Bluhm et H. Münkler (dir.), Gemeinwohl und Gemeinsinn. Historische Semantiken politischer Leitbegriffe, Berlin, Akademie Verlag GmbH, 2001, p. 85-107. 
BLOCH Marc, Les Rois thaumaturges. Étude sur le caractère surnaturel attribué à la puissance royale particulièrement en France et en Angleterre, Strasbourg-Paris, Istra, 1924.

BRUNI Francesco, « Immagini sacre, immagini profane, monogramma di Cristo », dans Id., La città divisa. Le parti e il bene comune da Dante a Guicciardini, Bologne, Il Mulino, 2003, p. 343-403.

BÜHRING Johannes, «Johanns von Capistrano, des andächtigen Vaters Aufenthalt in Arnstadt 1452 », Alt-Arnstadt. Beiträge zur Heimatkunde von Arnstadt und Umgebung, vol. 3, 1906, p. 83-95.

Chronica Fratris Nicolai Glassberger Ordinis Minorum Observantium, dans Analecta Franciscana, t. II, Firenze, Quaracchi, 1887.

DEBIAIS Vincent, « From Christ's Monogram to God's Presence. An Epigraphic Contribution to the Study of Chrismons in Romanesque Sculpture », dans J. F. Hamburger et B. M. Bedos-Rezak (dir.), Sign and Design. Script as Image in Cross-Cultural Perspective (300-1600 CE), Washington (D.C.), Dumbarton Oaks, 2016, p. 135-153.

ESCHENLOER Pierre, « Historia Wratislaviensis », fo 32b, dans Scriptores rerum silesiacarum, vol. 7, Breslau, 1872.

HAMBURGeR Jeffrey F. et BEDos-REZAK Brigitte Miriam (dir.), Sign and Design. Script as Image in CrossCultural Perspective (300-1600 CE), Washington (D.C.), Dumbarton Oaks, 2016.

HODEL Paul-Bernard, « D'une édition à l'autre. La lettre de saint Vincent Ferrier à Jean de Puynoix du 17 décembre 1403 », dans P.-B. Hodel et F. Morenzoni (dir.), « Mirificus Prcedicator ». À l'occasion du sixième centenaire du passage de saint Vincent Ferrier en pays romand, Actes du colloque d'Estavayer-le-Lac (7-9 octobre 2004), Rome, Istituto Storico Domenicano, 2006, p. 199-203 (précédemment éditée dans FAGEs Pierre-Henri, Histoire de saint Vincent Ferrier, apôtre de l'Europe, t. 1, Paris, Maison de la Bonne Presse, 1894, pièces justificatives, p. XXXI-XXXIII).

HofER Johannes, « Zur Predigttätigkeit des hl. Johannes Kapistran in deutschen Städten », Franziskanische Studien, vol. 13, 1926, p. 120-158.

HOFER Johannes, Johannes Kapistran. Ein Leben im Kampf um die Reform der Kirche, 2 vol., éd. O. Bonmann, Rome-Heidelberg, Kerle, 1964-1965.

JACOB Eugen, Johannes von Capistrano, Breslau, 1905-1911, II. Teil, Dritte Folge.

KRAs Pawel, MANIKOWSKA Halina, STARZYŃSKI Marcin et ZAJCHOWSKA-BOŁTROMIUK Anna (éds), Corpus epistolarum Ioannis de Capistrano / Correspondence of John of Capistrano, Vol. 1 : Letters Related to the History of Poland and Silesia (1451-1456), Varsovie-Lublin, Académie polonaise des Sciences / Wydawnictwo KUL, 2018.

LIPPENS Hugolin père, « S. Jean de Capistran en mission aux États bourguignons, 1442-1443. Essai de reconstitution de ses voyages et négociations à l'aide de documents inédits ", Archivum Franciscanum Historicum, t. 35, 1942, p. 263-66.

LONGPRÉ Ephrem, « Saint Bernardin de Sienne et le Nom de Jésus », Archivum Franciscanum Historicum, t. 28,1935 , p. 443-476 ; t. 29, 1936, p. 142-168 et p. 443-477 ; t. 30, 1937, p. 170-192.

ŁUSZCZKI Lucianus, De Sermonibus S. Ioannis a Capistrano. Studium historico-criticum, Rome, Pontificium Athenæum Antonianum, 1961.

Mathias Dörings Fortsetzung der Chronik von Dieterich Engelhusen, dans Riedel's Codex diplomaticus Brandenburgensis. Sammlung der Urkunden, Chroniken und sonstigen Geschichtsquellen für die Geschichte der Mark Brandenburg und ihrer Regenten, 4. Hauptteil, vol. 1, Berlin, 1862. 
MERLo Grado G., « Observance », dans A. Vauchez (dir.), Dictionnaire encyclopédique du Moyen Âge, t. 2, Paris, Cerf, 1997, p. 1095.

MÆLLER Bernd, Reichsstadt und Reformation, Gütersloh, Gütersloher Verlagshaus, 1962.

MONNET Pierre, « Ville et citoyenneté. En guise d'introduction », dans M. Caesar et M. Schnyder (dir.), Religion et pouvoir. Citoyenneté, ordre social et discipline morale dans les villes de l'espace suisse (XIV'-XVIII siècles), Neuchâtel, Alphil, 2014.

Muzzarelli Maria Giuseppina, Pescatori di uomini. Predicatori e piazze alla fine del medioevo, Bologne, Il Mulino, 2005.

NEUBNER Joseph, « Die Sachsenfahrt des heiligen Johannes Capistrano », St.-Benno-Kalender, vol. 81, 1931, p. 49-56.

OeXLE Otto Gerhard, « Les groupes sociaux du Moyen Âge et les débuts de la sociologie contemporaine ", Annales ESC, vol. 47, n 3, 1992, p. 751-765.

OSTORERo Martine, « Des papes face à la sorcellerie démoniaque (1409-1459) : une dilatation du champ de l'hérésie ? ", dans F. Mercier et R. Rosé, Aux marges de l'hérésie. Inventions, formes et usages polémiques de l'accusation d'hérésie au Moyen Âge, Rennes, PUR, 2018, p. 153-185.

PelLegrini Letizia, « Prédication et politique dans la péninsule italienne au $\mathrm{Xv}^{\mathrm{e}}$ siècle », dans F. Morenzoni (dir.), Preaching and Political Society. From Late Antiquity to the End of the Middle Ages / Depuis l'Antiquité tardive jusqu'à la fin du Moyen Âge, 16th Symposium of the International Medieval Sermon Studies Society (Saint-Maurice, Suisse, 18-22 juillet 2008), Turnhout, Brepols, 2013, p. 311-329.

PelLEgrini Letizia, «Faire en disant. Aspects performatifs de la prédication à l'automne du Moyen Âge », dans M. G. Muzzarelli (dir.), From Words to Deeds: The Effectiveness of Preaching in the Late Middle Ages, Turnhout, Brepols, 2014, p. 15-30.

PelLegrini Letizia et Viallet Ludovic, « Between christianitas and Europe: Giovanni of Capestrano as an Historical Issue », dans B. Roest et J. Mixson (dir.), Franciscan Studies, vol. 75, 2017, p. 5-26.

RICEUR Paul, La Symbolique du mal, Paris, Aubier, 1960.

ROEST Bert, « Giovanni of Capestrano’s Anti-Judaism Within a Franciscan Context: An Evaluation Based on Recent Scholarship », Franciscan Studies, vol. 75, 2017, p. 117-143.

Rosicz Sigismundus, « Gesta diversa transactis temporibus facta in Silesia et alibi », dans F. Wachter (éd.), Scriptores rerum silesiacarum, vol. 12 : Geschichtschreiber Schlesiens des XV. Jahrhunderts, Breslau, Josef Max \& Comp., 1883.

ROSIER-CATACH Irène, " "Res significata" et "modus significandi” : les enjeux linguistiques et théologiques d'une distinction médiévale ", dans S. Ebbesen (dir.), Sprachtheorien in Spätantike und Mittelalter, Tübingen, Gunter Narr Verlag, Geschichte der Sprachtheorie, 1995, p. 135-168.

RosieR-CATACH Irène, La Parole efficace. Signe, rituel, sacré, Paris, Seuil, 2004.

RubIN Miri, Gentile Tales. The Narrative Assault on Late Medieval Jews, Philadelphie, University of Pennsylvania Press, 2004 ( $1^{\text {re }}$ éd. Yale University Press, 1999).

SCHUSTER Peter, «Le rituel de la peine capitale dans les villes allemandes à la fin du Moyen Âge. Ruptures et continuités », dans J. Chiffoleau, C. Gauvard et A. Zorzi (dir.), Pratiques sociales et politiques judiciaires dans les villes de l'Occident à la fin du Moyen Âge, Rome, École française de Rome, 2007, p. 689-712. 
TURNER Victor, Dramas, Fields and Metaphors: Symbolic Action in Human Society, Ithaca, Cornell University Press, 1974.

VIALLET Ludovic, « Les deux bras du pape. Parcours croisés de Nicolas de Cues et Jean de Capistran en terre germanique (1451-1454) ", dans Les relations diplomatiques au Moyen Âge. Formes et enjeux, Actes du XLI ${ }^{\mathrm{e}}$ congrès de la SHMESP (Lyon, 3-5 juin 2010), Paris, Presses de la Sorbonne, 2011, p. 253-267.

VIALLET Ludovic, Les sens de l'observance. Enquête sur les réformes franciscaines entre l'Elbe et l'Oder, de Capistran à Luther (vers 1450-vers 1520), Münster, Lit Verlag, 2014.

VIALLET Ludovic, « The Name of God, the Name of Saints, the Name of the Order: Reflections on the 'Franciscan' Identity during the Observant Period », dans B. Roest et J. Uphoff (éds), Religious Orders and Religious Identity Formation, ca. 1420-1620. Discourses and Strategies of Observance and Pastoral Engagement, Leyde-Boston, Brill, 2016, p. 172-190.

VIALLET Ludovic, «L'autre Observance : les Reformati sub ministris et les "Colétans" ", dans Identità francescane agli inizi del Cinquecento, Atti del $45^{\circ}$ Convegno internazionale della Società internazionale di studi francescani (Assisi, 19-21 octobre 2017), Spolète, Centro Italiano di Studi Sull'Alto Medioevo, 2018, p. 121-139.

VIALLET Ludovic, « Mouvements paupéro-évangéliques, Wanderprediger, Lebensreform... : pour une grammaire du "réveil" religieux ", Germanosphères. Recherches clermontoises sur les pays germaniques, publication électronique (<https://hal-clermont-univ.archives-ouvertes.fr/ hal-01085061>).

VIALLET Ludovic, « Sous le soleil de Satan. Mouvements réformateurs mendiants et genèse de la chasse aux sorcières au XV ${ }^{e}$ siècle ", dans S. Simiz (dir.), Prêcher dans les espaces lotharingiens ( $X V^{e}$ XIX ${ }^{e}$ siècles), Paris, Garnier, à paraître.

VoGEL Johann Jacob, Leipzigisches Geschichtsbuch oder Annales, Leipzig, 1714.

VOLTMER Rita, « „Die fueßs an dem leichnam der christenhait / seind die hantwercks leüt. Arbeiter / bauleüt / und das gemayn volck...“" Die Straßburger „Unterschichten“ im polittheologischen System des Johannes Geiler von Kaysersberg », dans S. Schmitt et S. Klapp (éds), Städtische Gesellschaft und Kirche im Spätmittelalter. Kolloquium Dhaun 2004, Stuttgart, Franz Steiner Verlag, 2008, p. 189-232.

Voltmer Rita, « Political Preaching and a Design of Urban Reform: Johannes Geiler of Kaysersberg and Strasbourg ", Franciscan Studies, vol. 71, 2013, p. 71-88.

WEBER Max, « Die Stadt. Eine soziologische Untersuchung », Archiv für Sozialwissenschaft und Sozialpolitik, vol. 47, 1921, p. 621-772, trad. française La Ville, Paris, La Découverte, 2014.

WEBER Max, Wirtschaft und Gesellschaft. Studienausgabe, Tübingen, Mohr Siebeck, $1972^{5}$.

WERNER Matthias, «Landesherr und Franziskanerorden im spätmittelalterlichen Thüringen », dans D. Berg (dir.), Könige, Landesherren und Bettelorden. Konflikt und Kooperation in West- und Mitteleuropa bis zur Frühen Neuzeit, Werl, Dietrich-Coelde-Verlag, 1998, p. 331-360.

\section{NOTES}

1. Restée relativement en friche depuis la nouvelle édition (considérablement revue et complétée), par Ottokar Bonmann, de la biographie de Johannes Hofer, Johannes Kapistran. Ein Leben im Kampf um die Reform der Kirche, 2 vol., Rome-Heidelberg, Kerle, 1964-1965, 
l'historiographie de Jean de Capistran a été étoffée et renouvelée au cours de ces vingt dernières années, tant par des travaux individuels que par des entreprises collectives. La Grande Mission a été placée au cœur de l'ouvrage tiré de mon Habilitation à diriger des recherches, Les sens de l'observance. Enquête sur les réformes franciscaines entre l'Elbe et l'oder, de Capistran à Luther (vers 1450vers 1520), Münster, Lit Verlag, 2014, auquel je me permets de renvoyer pour de plus amples développements et des compléments bibliographiques. On pourra ajouter, parmi les publications les plus récentes, les contributions rassemblées par Bert Roest et James Mixson dans Franciscan Studies, vol. 75, 2017, notamment L. Pellegrini et L. Viallet, «Between christianitas and Europe: Giovanni of Capestrano as an Historical Issue », p. 5-26. Il est difficile de ne pas renvoyer à l'excès à ses propres travaux, lorsque l'on a consacré plusieurs années à un objet d'étude et multiplié les publications à son sujet ; le lecteur voudra bien considérer qu'il s'agit moins, dans ces pages, de céder aux délices de l'autocitation que d'apporter sa pierre à une réflexion issue de la rencontre entre un historien et des «littéraires" autour d'un passionnant terrain d'enquête, celui de la prise de parole à l'aube de la Modernité. Cette contribution retrace ainsi, à sa façon, un itinéraire de recherche, comme en témoigne l'usage volontaire, mais le plus modéré possible, de la première personne du singulier.

2. Chronica Fratris Nicolai Glassberger Ordinis Minorum Observantium, dans Analecta Franciscana, t. II, Firenze, Quaracchi, 1887, p. 331.

3. Ibid., p. 346.

4. Comme le montre notamment l'action de Nicolas de Cues, officiellement légat pontifical (contrairement à Capistran) : si les itinéraires des deux hommes furent parallèles au début de la Grande Mission, ils n'eurent ni les mêmes pratiques, ni sans doute le même succès. Voir L. Viallet, «Les deux bras du pape. Parcours croisés de Nicolas de Cues et Jean de Capistran en terre germanique (1451-1454)", dans Les relations diplomatiques au Moyen Âge. Formes et enjeux, Actes du $\mathrm{XLI}^{\mathrm{e}}$ congrès de la SHMESP (Lyon, 3-5 juin 2010), Paris, Presses de la Sorbonne, 2011, p. 253-267.

5. "Predicavit die cinerum in ecclesia sancte Elisabeth deinde in foro salis quasi singulis diebus latine [14 février], dominica judica ostendit speculum terribile alias ein Hirnschedel et imaginem sancti Bernhardi [18 mars] factaque fuit solemnis processio de foro salis per dominum episcopum ambarum ecclesiarum parochialium et patris et fratrum ad novam hereditationem in nova civitate pro fratribus noviter erectam. » (S. Rosicz, " Gesta diversa transactis temporibus facta in Silesia et alibi », dans F. Wachter (éd.), Scriptores rerum silesiacarum, vol.12: Geschichtschreiber Schlesiens des XV. Jahrhunderts, Breslau, Josef Max \& Comp., 1883, p. 63)

6. Voir J. Hofer, «Zur Predigttätigkeit des hl. Johannes Kapistran in deutschen Städten», Franziskanische Studien, vol.13, 1926, p.149-150; J. Neubner, «Die Sachsenfahrt des heiligen Johannes Capistrano ", St.-Benno-Kalender, vol. 81, 1931, p. 55. La mort et le Jugement furent des thèmes abordés par Capistran à Leipzig: voir L. Łuszczki, De Sermonibus S. Ioannis a Capistrano. Studium historico-criticum, Rome, Pontificium Athenæum Antonianum, 1961, p. 277-278 (et l'index chronologico-thématique, p. 308), qui souligne le degré d'intensité extrême - rarement atteint selon lui chez Capistran - de cette prédication sur la mort, sans toutefois mentionner l'usage d'un crâne.

7. E. Jacob, Johannes von Capistrano, Breslau, 1905-1911, II. Teil, Dritte Folge, p.135, cité par G. Buchwald, "Johannes Capistranos Predigten in Leipzig 1452 », Beiträge zur Sächsischen Kirchengeschichte, Heft 26, 1912, Leipzig, 1913, p. 149.

8. Voir J. Hofer, Johannes Kapistran, ouvr. cité, t. 1, p.313-320 («Die Heiligsprechung Bernhardins »), p. 353-357 ( Große Volksmission in Brescia») et p. 360 (commentaire de l'illustration : retable réalisé par Jean Figuera pour le couvent de Cagliari, en Sardaigne). Dans la Cronaca (1437-1468) de Cristoforo da Soldo, le passage sur le séjour à Brescia, du 9 au 16 février 1451, se situe aux p. 865-869 de l'édition de Milan, 1732 (Rerum Italicarum Scriptores, XXI-3), aux p. 100-103 de celle de Bologne, 1938. 
9. J. J. Vogel, Leipzigisches Geschichtsbuch oder Annales, Leipzig, 1714, p. 56 : «Und als er einsmahls nach gehaltener Predigt auff dem Marckte einen Kopff eines verstorbenen Heiligen von der Cantzel gezeiget, sind dadurch in die 60 Universitäts-Verwandten bewogen worden, dass sie das weltliche Leben verlassen und zu Franciscaner-Mönchen sich einkleiden lassen. »

10. Avec une variante : "Jésus et Miséricorde». Voir J. Bühring, "Johanns von Capistrano, des andächtigen Vaters Aufenthalt in Arnstadt $1452 »$, Alt-Arnstadt. Beiträge zur Heimatkunde von Arnstadt und Umgebung, vol. 3, 1906, p. 88.

11. Selon le mot de Grado G. Merlo, "Observance", dans A. Vauchez (dir.), Dictionnaire encyclopédique du Moyen Âge, t. 2, Paris, Cerf, 1997, p. 1095.

12. P. Eschenloer, "Historia Wratislaviensis ", fo $32 \mathrm{~b}$, dans Scriptores rerum silesiacarum, vol. 7 , Breslau, 1872, p. 5: «In Wratislavia nostra novum construi claustrum curavit, spurcicia ludorum abstulit, superbiam utriusque sexus repressit, adulteria nauseare fecit et admodum accendit populum Wratislaviensem zelo devocionis, ut non cives sed ferme religiosi cogniti sunt. »

13. Ce dossier est abordé dans L. Viallet, Les sens de l'observance, ouvr. cité, chap. 3, p. 129-158. Voir aussi M. Rubin, Gentile Tales. The Narrative Assault on Late Medieval Jews, Philadelphie, University of Pennsylvania Press, 2004 ( $1^{\text {re }}$ éd. Yale University Press, 1999), en particulier p. 119-128 («Preaching and Incitement : Wrocław, $1453 »)$ sur le cas de Breslau et plus largement le lien entre prédication et accusations de profanation d'hostie par des Juifs, de Vincent Ferrier à Capistran. Sur le rôle de Capistran dans les massacres de Silésie, il faut être moins nuancé que ne l'est Bert Roest, «Giovanni of Capestrano's Anti-Judaism Within a Franciscan Context: An Evaluation Based on Recent Scholarship ", Franciscan Studies, vol. 75, 2017, p. 134-136.

14. Voir R. Voltmer, „Die fueßs an dem leichnam der christenhait / seind die hantwercks leüt. Arbeiter / bauleüt / und das gemayn volck...“ Die Straßburger „Unterschichten“ im polittheologischen System des Johannes Geiler von Kaysersberg ", dans S. Schmitt et S. Klapp (dir.), Städtische Gesellschaft und Kirche im Spätmittelalter. Kolloquium Dhaun 2004, Stuttgart, Franz Steiner Verlag, 2008, p. 189-232, en particulier p. 222-223 ; ou, plus synthétique, R. Voltmer, «Political Preaching and a Design of Urban Reform: Johannes Geiler of Kaysersberg and Strasbourg ", Franciscan Studies, vol. 71, 2013, p. 71-88.

15. Remarques et pistes de réflexion dans L. Viallet, "Sous le soleil de Satan. Mouvements réformateurs mendiants et genèse de la chasse aux sorcières au Xv siècle », dans $\mathrm{S}$. Simiz (dir.), Prêcher dans les espaces lotharingiens ( $X V^{e}-X I X^{e}$ siècles), Paris, Garnier, à paraître. Sur la notion d'hérésie et sa véritable « dilatation » sous l'impulsion des pouvoirs, voir le récent volume dirigé par Franck Mercier et Isabelle Rosé, Aux marges de l'hérésie. Inventions, formes et usages polémiques de l'accusation d'hérésie au Moyen Âge, Rennes, PUR, 2018, en particulier la contribution de Martine Ostorero, «Des papes face à la sorcellerie démoniaque (1409-1459) : une dilatation du champ de l'hérésie?", p. 153-185.

16. «[...] nec volebat quod crucem faceret vel Jesum Christum nominaret quia, ut asserit dicta delata [...] dyabolus dicebat quod quando audiebant Jesum nominare, ipse et omnes demones Inferni torquebantur et inclinabant se et genua flexunt. » (Archives départementales de l'Isère, B 4356, fo 340)

17. Voir l'article classique d'Ephrem Longpré, "Saint Bernardin de Sienne et le Nom de Jésus ", Archivum Franciscanum Historicum, t. 28, 1935, p. 443-476 ; t. 29, 1936, p. 142-168 et p. 443-477; t. 30, 1937, p. 170-192; ainsi que l'ouvrage de F. Bruni, La città divisa. Le parti e il bene comune da Dante a Guicciardini, Bologne, Il Mulino, 2003, en particulier le chapitre "Immagini sacre, immagini profane, monogramma di Cristo ", p. 343-403.

18. J. F. Hamburger et B. M. Bedos-Rezak (dir.), Sign and Design. Script as Image in Cross-Cultural Perspective (300-1600 CE), Washington (D.C.), Dumbarton Oaks, 2016, p. 10. Voir en particulier, dans cet ouvrage, les réflexions introductives des deux éditeurs et la contribution de Vincent Debiais, "From Christ's Monogram to God's Presence. An Epigraphic Contribution to the Study of Chrismons in Romanesque Sculpture », p. 135-153. 
19. On pensera à la lettre adressée par Vincent Ferrier depuis Genève en décembre 1403 au maître général des dominicains Jean de Puinoix, dans laquelle il racontait avoir rencontré, dans le diocèse de Lausanne, des populations vouant un culte au Soleil. La lettre a été éditée dans P.-H. Fages, Histoire de saint Vincent Ferrier, apôtre de l'Europe, t. 1, Paris, Maison de la Bonne Presse, 1894, pièces justificatives, p. XXXI-XXXIII, puis récemment par P.-B. Hodel, « D'une édition à l'autre. La lettre de saint Vincent Ferrier à Jean de Puynoix du 17 décembre 1403 », dans P.-B. Hodel et F. Morenzoni (dir.), "Mirificus Praedicator». À l'occasion du sixième centenaire du passage de saint Vincent Ferrier en pays romand, Actes du colloque d'Estavayer-le-Lac (7-9 octobre 2004), Rome, Istituto Storico Domenicano, 2006, p. 199-203.

20. Le symbole ne nous fait pas connaître ce qu'est une chose, il « donne à penser » au sujet de cette chose, selon le mot de Paul Ricœur (La Symbolique du mal, Paris, Aubier, 1960); il nous aide à progresser, par analogie, dans la recherche du sens. Au sujet de la réflexion sur les modi significandi et la différence entre signe et symbole, essentielle pour appréhender la théorie chrétienne des sacrements, voir les travaux d'Irène Rosier-Catach, " "Res significata" et "modus significandi": les enjeux linguistiques et théologiques d'une distinction médiévale ", dans S. Ebbesen (dir.), Sprachtheorien in Spätantike und Mittelalter, Tübingen, Gunter Narr Verlag, Geschichte der Sprachtheorie, 1995, p. 135-168, notamment La Parole efficace. Signe, rituel, sacré, Paris, Seuil, 2004.

21. Sur ces deux enjeux essentiels des réformes religieuses $d u \mathrm{xv}^{\mathrm{e}}$ siècle, celui de la dénomination et celui de la lutte contre la déviance, qui me paraissent liés et en induire bien d'autres, je me permets de renvoyer aux remarques et pistes de réflexion présentées dans L. Viallet, « The Name of God, the Name of Saints, the Name of the Order: Reflections on the 'Franciscan' Identity during the Observant Period ", dans B. Roest et J. Uphoff (dir.), Religious Orders and Religious Identity Formation, ca.1420-1620. Discourses and Strategies of Observance and Pastoral Engagement, LeydeBoston, Brill, 2016, p. 172-190, ainsi que L. Viallet, "Sous le soleil de Satan », art. cité. Si l'on essaie de réfléchir sur la corrélation entre la montée en puissance du discours réformateur et les forces qui ont travaillé à la constitution du crime de sorcellerie satanique (le discours observant ayant amplifié, déformé, contribué à métamorphoser et uniformiser - en particulier par la diabolisation - un matériau culturel aux sources diverses), il n'est pas possible de considérer que le positionnement et le discours de Bernardin de Sienne par rapport à la figure de la sorcière en 1427 aient pu être déterminés par la seule volonté de ce dernier de se réhabiliter auprès de l'opinion toscane après son procès pour hérésie, comme le suggère Émilie Zanone, « De l'attente du jugement divin aux bûchers: le stéréotype de la sorcière dans la prédication en langue vulgaire de Bernardin de Sienne », Cahiers d'études italiennes, n 15, 2012, p. 96-97 («Faut-il se demander si, au sortir de son procès romain, Bernardin de Sienne, prédicateur franciscain et futur saint, n'apparaît plus comme un modèle chrétien et cherche sa rédemption auprès de ses pères en accusant ses ouailles d'alimenter un dangereux péril pour le salut de la chrétienté ?»).

22. Mathias Dörings Fortsetzung der Chronik von Dieterich Engelhusen, dans Riedel's Codex diplomaticus Brandenburgensis. Sammlung der Urkunden, Chroniken und sonstigen Geschichtsquellen für die Geschichte der Mark Brandenburg und ihrer Regenten, 4. Hauptteil, vol. 1, Berlin, 1862, p. 225 : «Et ut videretur coram hominibus in locis prophanis ad hoc in foro civitatum cum multo apparatu preparatis, ubi tamen ecclesiarum solempnium et monasteriorum erat numerus, missas celebrare consueverat, nec in aliquo loco nisi multum exaltato et ornato predicabat. [...] et si quis contractus vel claudus ex confidencia orta ex rumore premissorum se putavit melius stare, illum procedere socii sui compulerunt, clamantes et magno cum tumultu populum ad clamandum ihesus provocantes; tulerunt eorum baculos et sustentacula, suspendentes ea in ecclesia coram ymagine sancti Bernhardi [sic]. Fama tamen erat, quod sic curati recidivantes baculos ut plurimum repecierunt. Hic recepit multos undecunque venientes ad suam familiam, et loca pro construendis monasteriis de observancia nuncupandis, pro illis recolligendis, peciit a Dominis et communitatibus, et optinuit in provincia Saxonie et aliarum magnam turbacionem. » 
23. M. Bloch, Les Rois thaumaturges. Étude sur le caractère surnaturel attribué à la puissance royale particulièrement en France et en Angleterre, Strasbourg-Paris, Istra, 1924, III («L'interprétation critique du miracle royal »), chapitre unique, § 2, p. 420-429 dans l'édition de 1961: «Comment on a cru au miracle royal ».

24. L'épisode est rapporté par Christophe de Varèse, Vita S. Joannis a Capistrano, scripta a Fr. Christophoro a Varisio, ex ms. Aracoelitano, dans Acta Sanctorum octobris, t. 10, Bruxelles, 1861, c. 149 , p. 523 : «In ipsa civitate, cum esset vicarius generalis, et appropinquaret festum Pentecostes, memor bonitatis divinae, per quam missus est Spiritus Sanctus in discipulos, coram fratribus, adstantibus brachiis in modum Crucis extensis, vertit se ad quatuor partes mundi, scilicet Orientem et Occidentem, Septemtrionem, et Meridiem dicens: "Vos estis mihi testes, quod omnes fideles, in omnibus mundi partibus existentes, ad nostram confraternitatem recipio, eisque, quantum possum, participationem omnium bonorum concedo". »

25. L. Viallet, "Mouvements paupéro-évangéliques, Wanderprediger, Lebensreform... : pour une grammaire du "réveil" religieux", Germanosphères. Recherches clermontoises sur les pays germaniques, publication électronique (<https://hal-clermont-univ.archives-ouvertes.fr/ hal-01085061>).

26. L. Pellegrini, «Faire en disant. Aspects performatifs de la prédication à l'automne du Moyen Âge ", dans M. G. Muzzarelli (dir.), From Words to Deeds: The Effectiveness of Preaching in the Late Middle Ages, Turnhout, Brepols, 2014, p. 15-30. Sur le concept de «drame social ", «public épisodes of tensional irruption", voir V. Turner, Dramas, Fields and Metaphors: Symbolic Action in Human Society, Ithaca, Cornell University Press, 1974 (ici p. 33).

27. Voir notamment L. Pellegrini, «Prédication et politique dans la péninsule italienne au $\mathrm{Xv}^{\mathrm{e}}$ siècle ", dans F. Morenzoni (dir.), Preaching and Political Society. From Late Antiquity to the End of the Middle Ages / Depuis l'Antiquité tardive jusqu'à la fin du Moyen Âge, 16th Symposium of the International Medieval Sermon Studies Society (Saint-Maurice, Suisse, 18-22 juillet 2008), Turnhout, Brepols, 2013, p. 311-329 ; M. G. Muzzarelli, Pescatori di uomini. Predicatori e piazze alla fine del medioevo, Bologne, Il Mulino, 2005.

28. Voir M. Werner, «Landesherr und Franziskanerorden im spätmittelalterlichen Thüringen », dans D. Berg (dir.), Könige, Landesherren und Bettelorden. Konflikt und Kooperation in West- und Mitteleuropa bis zur Frühen Neuzeit, Werl, Dietrich-Coelde-Verlag, 1998, p. 331-360, en particulier p. 350-353 pour les relations du duc Guillaume III avec Capistran et la rencontre des 5-9 septembre 1452. Son petit neveu fut le protecteur de Luther, le duc de Saxe Frédéric III, qui l'accueillit à la Wartbourg en 1521-1522.

29. Comme je l'ai montré dans L. Viallet, Les sens de l'observance, ouvr. cité, p. 207-272.

30. Dans une bibliographie surabondante, voir M. Weber, Wirtschaft und Gesellschaft. Studienausgabe, Tübingen, Mohr Siebeck, $1972^{5}$ et Id., "Die Stadt. Eine soziologische Untersuchung", Archiv für Sozialwissenschaft und Sozialpolitik, vol.47, 1921, p.621-772, trad. française La Ville, Paris, La Découverte, 2014 ; O. G. Oexle, « Les groupes sociaux du Moyen Âge et les débuts de la sociologie contemporaine ", Annales ESC, vol. 47, n 3, 1992, p. 751-765.

31. Voir la contribution stimulante de Peter Blicke à la réflexion, «Der Gemeine Nutzen. Ein kommunaler Wert und seine politische Karriere », dans H. Bluhm et H. Münkler (dir.), Gemeinwohl und Gemeinsinn. Historische Semantiken politischer Leitbegriffe, Berlin, Akademie Verlag GmbH, 2001, p. 85-107.

32. B. Mœller, Reichsstadt und Reformation, Gütersloh, Gütersloher Verlagshaus, 1962, p. 15 : «Die deutsche Stadt des Spätmittelalters hat eine Neigung, sich als „corpus christianum“ im kleinen zu verstehen.» Il en va de même, d'ailleurs, pour la notion de «communauté sacrée » (Sakralgemeinschaft).

33. Peter Schuster a bien montré la façon dont, à partir du $\mathrm{xv}^{\mathrm{e}}$ siècle, dans l'Empire, les exécutions ont fait l'objet de véritables mises en scène religieuses. Dans le coutumier de la ville franconienne de Volkach composé en 1504 (le Salbuch), une miniature en couleurs représente une 
scène de pendaison d'un voleur de vin ; le chemin qui mène à la potence est un Chemin de Croix et l'endroit où a lieu l'exécution est nommé locus calvarie. D'une façon générale, les scènes d'exécution de cette époque contiennent toujours des allusions à la Passion. Quant aux textes, ils témoignent de l'engagement du public, touché par le supplice d'un condamné dont ils avaient régulièrement pitié. L'intégration d'éléments religieux dans les rituels d'exécution (notamment, leur accès à la communion et le fait qu'un clerc accompagnât le condamné sur le chemin de la potence en portant une croix devant lui) montre que dans l'Empire, «vers 1500, le droit des condamnés à être membres à part entière de la communitas christiana s'était imposé ", non sans résistances (P. Schuster, «Le rituel de la peine capitale dans les villes allemandes à la fin du Moyen Âge. Ruptures et continuités ", dans J. Chiffoleau, C. Gauvard et A. Zorzi (dir.), Pratiques sociales et politiques judiciaires dans les villes de l'occident à la fin du Moyen Âge, Rome, École française de Rome, 2007, p. 689-712, ici p. 704).

34. P. Monnet, «Ville et citoyenneté. En guise d'introduction», dans M. Caesar et M. Schnyder (dir.), Religion et pouvoir. Citoyenneté, ordre social et discipline morale dans les villes de l'espace suisse (XIV'-XVIII ${ }^{e}$ siècles), Neuchâtel, Alphil, 2014, p. 28.

35. La Chronica Fratrum Minorum de Observancia Provincie Bohemie est conservée à la bibliothèque du Musée national de Prague, Sign. VIII F 75 et devrait bientôt être éditée. Je la cite ici d'après F. Doelle, Die Observanzbewegung in der sächsischen Franziskanerprovinz bis zum Generalkapitel von Parma 1529, Münster, Verlag der Aschendorffschen Verlagsbuchhandlung, 1918, p. 226 (Beilagen, 7) : «Allegantes contra nos, quod non haberemus studia neque horas caneremus, ipsi essent de vera et regulari observancia, nostram observanciam non mediocriter infamantes, asserentes nos verecundari paterni nominis sancti Francisci, et faceremus nos nuncupari Bernnardinenses et ipse sanctus Bernhardinus, si non esset canonisatus propter separacionem a conventualibus, nunquam canonisaretur, quasi ecclesia errasset in sua canonisacione. Ecce perfidia pessimorum obstinatorum deformatorum ! »

36. Cité par M. Bihl, «Fra Bonifacio da Ceva $(\dagger 1517)$ e i suoi giudizi su Bernardino da Siena », Studi Francescani, vol. 42, 1945, p. 171.

37. Colette de Corbie rencontra Jean de Capistran, entre Besançon et Dôle, en novembre 1442, mais l'entrevue ne se déroula pas forcément dans l'atmosphère de parfaite convergence de vues qu'évoqua naguère le père Hugolin Lippens, « $\mathrm{S}$. Jean de Capistran en mission aux États bourguignons, 1442-1443. Essai de reconstitution de ses voyages et négociations à l'aide de documents inédits", Archivum Franciscanum Historicum, t. 35, 1942, p.263-66. Il y eut véritablement, dans les années 1440 , un choix des frères et de leur « mère », Colette, en forme de refus.

38. Présentation de ces mouvements dans L. Viallet, «L'autre Observance:les Reformati sub ministris et les "Colétans" ", dans Identità francescane agli inizi del Cinquecento, Atti del $45^{\circ}$ Convegno internazionale della Società internazionale di studi francescani (Assisi, 19-21 octobre 2017), Spolète, Centro Italiano di Studi Sull'Alto Medioevo, 2018, p. 121-139.

39. «O filii dilectissimi, haecne est doctrina quam vos, cum adhuc vobiscum essem, pluribus sermonibus docui ? Nonne praemissa omnia a vobis esse servanda, quantum potui, persuasi ? An forte tacui vobis, illa per patres nostros Italicos hactenus servata fuisse, et modo quidem servari ? " Cette lettre fut envoyée par Jean de Capistran aux observants de Cracovie le 2 janvier 1455 afin de les ramener à plus de rigueur. Éditée par L. Wadding, Annales Minorum seu trium ordinum a S. Francisco institutorum, t. 12, éd. J. M. Fonseca, Firenze, Quaracchi, 1932, p. 341-343, elle vient de faire l'objet d'une nouvelle édition dans P. Kras, H. Manikowska, M. Starzyński et A. Zajchowska-Bołtromiuk (dir.), Corpus epistolarum Ioannis de Capistrano / Correspondence of John of Capistrano, Vol. 1: Letters Related to the History of Poland and Silesia (1451-1456), Varsovie-Lublin, Académie polonaise des Sciences / Wydawnictwo KUL, 2018, lettre $\mathrm{n}^{\circ} 36$.

40. Pour reprendre le titre de la thèse désormais classique de Nicole Bériou, L'avènement des maîtres de la parole. La prédication à Paris au XIII siècle, 2 vol., Paris, Institut d'études augustiniennes, 1998. 


\section{RÉSUMÉS}

Cette étude est consacrée à la mission que mena en Europe centrale le franciscain réformateur Jean de Capistran de mai 1451 à octobre 1456. Le projet de ce prédicateur à succès était une réforme religieuse, mais aussi, plus largement, une réforme de la société. Il mit en œuvre un art de la prédication élaboré par les prédicateurs italiens, en particulier Bernardin de Sienne, et fondé non sur le seul usage de la parole, mais aussi sur le visuel et le miraculeux. Mis au service d'une réforme franciscaine (l'observance sub vicariis dite " cismontaine ») et très critiqué par les adversaires de Capistran, l'acte de prédication doit donc être considéré, par l'historien, dans sa dimension performative.

Questo studio è dedicato alla missione condotta in Europa centrale dal riformatore francescano Giovanni da Capestrano dal maggio 1451 all'ottobre 1456. Il progetto di questo predicatore di successo era una riforma religiosa, ma anche, più largamente, una riforma della società. La sua era un'arte della predicazione elaborata dai predicatori italiani, in particolare Bernardino da Siena, e fondata sull'uso della parola, ma anche sul visivo e sul miracoloso. Messa al servizio di una riforma francescana (la cosiddetta Osservanza sub vicariis) e molto criticata dagli oppositori di Capestrano, la predicazione deve quindi essere considerata qui dallo storico nella sua dimensione performativa.

This study is devoted to the mission led in central Europe by the Franciscan reformer John of Capestrano from May 1451 to October 1456. The project of this successful preacher was a religious reform, but also, more broadly, a reform of society. He implemented an art of preaching elaborated by the Italian preachers, especially Bernardin of Siena, and founded not on the sole use of the word, but also on the visual and the miraculous. Put at the service of a Franciscan reform (the Observance sub vicariis) and much criticized by the opponents of Capestrano, the act of preaching must therefore be considered by the historian in his performative dimension.

\section{INDEX}

Mots-clés : prédication, Europe centrale, Jean de Capistran, ordre franciscain Keywords : preaching, Central Europe, John of Capestrano, Francescan order Parole chiave : predicazione, Europa centrale, Giovanni da Capestrano, ordine francescano

\section{AUTEUR}

\section{LUDOVIC VIALLET}

Université Clermont Auvergne.

ludovic.viallet@uca.fr 